\title{
Impact of IoT Technologies on Smart City Infrastructure: Current Applications and Future Potential
}

\author{
Joshi Sujata, Chirputkar Abhijit, Barshekee Chanda
}

\begin{abstract}
With the advent of digitization, upcoming technologies like Internet of Things (IOT) are being used by organizations to manage their business, infrastructure as well as assets. In order to make the IT Infrastructure more efficient, upcoming technologies like Internet of things play a very important role as IoT has increased the scale of the storage and the server spaces, improved the internet connectivity thereby leading to a smarter IT infrastructure. Although IoT adoption is taking place rapidly at the enterprise and industrial level; there is a dearth of academic literature in this area. Hence the objective of the paper is to study the adoption of various IoT technologies for smart city infrastructure, understand the impact/benefits of these technologies and propose future potential applications which can be used for smart infrastructure. A case study approach has been adopted for this research wherein various use cases in the IT industry have been analysed with respect to the adoption of IoT technologies 0066or smart city infrastructure and the benefits of the same to the various sectors. The study will be useful for academicians, and practitioners, and Government officials to design and develop solutions for smart city infrastructure that will add to wellbeing of society at large.
\end{abstract}

Keywords-IoT, IT Infrastructure management, Smart City, Digitization.

\section{INTRODUCTION}

India is amongst the fast developing countries of the world. This has resulted in high growth in the urban population which has necessitated the efficient management of resources and infrastructure in the urban areas. The smart city initiative of the Indian Government is one of the ways of encouraging the efficient management of infrastructure as well as resources. Infrastructure systems are required for cities to develop and sustain their resources like water, transportation, energy, etc. With respect to smart cities, infrastructure development focuses on smart development to ensure proper terms of liveability (Cavada, Hunt \& Rogers 2017) [1]. For a smart city to be fully functional, a lot of factors in terms of IT Infrastructure like strong telecommunication network, strong internet connectivity, wireless broadband connection,

Revised Version Manuscript Received on 10 September, 2019.

Joshi Sujata, Professor, Symbiosis Institute of Telecom Management, constituent of Symbiosis International (Deemed University), Lavale, Pune, India.

(Email:sjoshi@sitm.ac.in)

ChirputkarAbhijit, Director, Symbiosis Institute of Telecom Lavale, Pune, India.

(Email:director@sitm.ac.in)

BarshekeeChanda, Student, Symbiosis Institute of Telecom Management, constituent of Symbiosis International (Deemed University), Lavale, Pune, India

(Email: barshekee.chanda1820@sitm.ac.in) Management, constituent of Symbiosis International (Deemed University),

broadcast network and several sensors are required to be integrated into one (Chaudhary S, 2018) [2]. This ensures consistent tracking, monitoring, recognition and exchange of information; thereby justifying the term "smart cities".

In order to make the IT Infrastructure more efficient, upcoming technologies like Internet of things play a very important role. In 1980, IoT concept was drafted when at Carnegie Mellon University; a coke machine checked the inventory to record if the drinks were cold or not when connected to the internet (Xcube LABS, 2017) [3]. IoT has impacted our lives massively and has laid its deep roots in developing countries like India where it is being inculcated at every step. According to a report by Deloitte, India has about 60 million IoT devices and by the end of 2020 the number of devices is expected to grow to 1.9 billion (Gurnaney T, 2017) [4]. According to NASSCOM's report, the IoT market in India is estimated to reach $\$ 15$ billion by the end of 2020 (Gurnaney T, 2017) [4]. The tier 2 and tier 3 cities of India will experience a major change and upgradation as soon as some of the IoT projects are deployed (Gurnaney T, 2017) [4]. Based on India's demographics and geography, there will be many use cases of IoT in India. Recently, it has been reported that, SAP has partnered with Vodafone so that IoT solutions adoption is bolstered in the Indian economy. India is ingraining IoT in supply chain management and several logistics firms are using relay model of service to connect cities commuted by truck making travel and logistics simpler (Steinbach R, 2018)[5]. Use of smart devices in the Indian agriculture market will help predict the productivity and ensure apt use of energy and resources like fertilizer and water, etc.

As stated from the studies above, the role of IoT in creating smart IT infrastructure assumes a lot of importance. Hence this paper is an attempt to add to the literature on IT Infrastructure for smart cities. Hence the objective of the paper is to understand the impact of IoT applications on IT Infrastructure and shed light on future potential applications. We propose to do the same by studying various use cases in the IT industry.

\section{LITERATURE REVIEW}

Smart cities based on cloud computing is a smart and the modern way to address the complexities faced in today's world. With the help of IoT it has become possible to manage

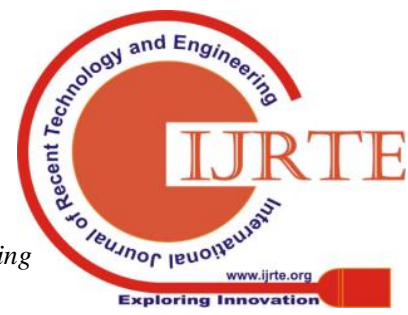


a city's transportation, its infrastructure, its pollution, its energy, etc. with maximum feasibility. Various studies have been done in academic literature which suggests the important role of IoT for smart IT infrastructure. Lea \&Blackstock (2014) [6] in their study discussed few of the IoT techniques adopted or were in process of adoption to ensure that cities can function on IoT Infrastructure. Wi-Fi scanners and magnetic sensors can be used predominantly to manage the traffic and to make the system more efficient. Different kinds of cloud infrastructure can be adopted like hybrid cloud or integrated cloud or hub to hub inter-operatibility for enabling new services across a city. J. Paradells et al (2014) [7] elaborated on the cost effective network management techniques which have proven to give a positive result when implemented. Ouerhani et al (2016)[8] had worked on the dynamic controlling issue of the street light and with the help of integration of sensors to the IoT platform solved the problem, thereby saving energy $56 \%$ more than the classical systems. According to the study by Perera et al (2017) [9], Fog computing needs to work hand in hand with Cloud computing to negate the drawbacks and to ensure positive yield. In this survey data analytics is used to study the data and then detecting the behaviour. Ganesh (2017)[10] in their study focused on the importance of Big Data while trying to implement the smart city infrastructure. This paper majorly focuses on the collection of Data and use of Hadoop with Spark or Storm to study and analyse the data networks.

The importance of IoT while implementing smart cities has been elaborated by Nassar et al (2018) [11] in their research. They pointed out that with the growing human index, the necessities and the requirements also keeps increasing. This needs well planned management which the concept of smart cities will help in achieving by amalgamating IoT in the day to day lives, thereby defining the way humans live. Zhang et al. (2019) [12] pointed out in their study that IoT goes hand in hand with edge computing when it comes to building a smart city and several sensors along with edge devices need to be built in order to facilitate a smart network. This tends to reduce the latency as well as facilitate a cost effective process. Thus for a smart city to be fully functional the algorithm needs to be robust and light weight in order to capture and process massive data for yielding positive output. Parishwad\& Singh (2014) [13] pointed out that urbanization and the modernization policy in India has been subjugated to an integrated ICT governance system. E-governance constricts its focus to e-procurement, carbon emission control as well as pollution control, developing smart buildings, online learning platform about each city, etc. This will help facilitate smart city movement in India and bring about this change. Sensors are really important when it comes to implementation of the smart city project and are also expensive. Tiwary (2016)[14] discussed in his paper the criteria considered in order to name a city in India as a 'Smart City'. Few of the pointers are expanding the opportunity for housing for the general public. In an area based development there should be an opportunity for mixed land use, controlling pollution and make the localities walkable thus promoting safety and a healthy lifestyle.

Hence in this paper we are aiming at finding an optimal solution for implementation of smart cities in India with the being generated from the installed sensors and from the

help of upcoming technologies like IoT, taking into account the importance of keeping data private, the robustness of the data, the need for fast and economical processing of data. We will be focusing on IoT applications and its effect on IT infrastructure by analysing several cases which India has been trying to implement or can implemented in the future.

\section{RESEARCH METHOD}

A case study approach has been adopted for this research wherein various use cases in the IT industry have been analysed with respect to the adoption of IoT technologies for smart city infrastructure and the benefits of the same to the various sectors. The data for this study has been collected through various online databases, whitepapers, articles and reports. Collected literature was then analyzed for relevance to the topic.

Yin (1984) [15] defines the case study research method "as an empirical inquiry that investigates a contemporary phenomenon within its real-life context; when the boundaries between phenomenon and context are not clearly evident; and in which multiple sources of evidence are used." As opined by Gummesson (1981) [16], case study as a method of research has several strengths; one of them being the ability to get a holistic picture of the event/phenomena under investigation and the second being its ability to provide an all round perspective since many sources/events/ phenomena have been observed related to the topic under investigation. Researchers like McDonough and McDonough (1997) [17] have categorized case studies as interpretive; wherein the data is interpreted by the researcher with an aim of reinforcing, or questioning the assumptions made by them for the topic under consideration; and evaluative categorization of case study wherein researcher goes one step ahead and adds his own acumen to the findings for the topic under consideration.

The following were the research questions addressed through thus study:

1) Do IoTbased applications play a significant role in IT infrastructure management for making cities smarter.

2) Are there specific use cases of IoT applications in smart IT infrastructure management?

\section{IOT APPLICATIONS, ITS BENEFITS AND USE CASES: RESULTS \& DISCUSSIONS}

In this section we propose to discuss various use cases of IoT applications, the technology behind the application, benefits of the applications and its impact on business. IoT has enabled regular and ordinary objects to be used intelligently thus making them interactive. This promises a lot of potential for the present and the near future. With the help of edge network technology the data being gathered can be analysed and certain conclusions can be drawn, which will help in prediction of the object's behaviour based on scenarios. (Hou et al (2016) [18]. The emergent IoT technology is helping in urban management of waste, smart lightning, smart parking, etc. For setting up an end to end connected IoT device for a smart city there needs to be a very

Published By:

Blue Eyes Intelligence Engineering 
well connected network along with proper modules of analytics being implemented on the several connectivity platforms. India is also trying to implement and trying to get the infrastructure in place for finding the apt solution for making a city 'smart city'. The following examples depict the several use cases being implemented in India or worldwide.

\subsection{IOT application 1: Relay Truck System:}

\subsubsection{Technology adopted}

IoT is bringing in a major change in every nook and corner and it has played a unique and important role in transforming the logistics industry. This sector used to suffer from problems like poor turnaround time, delay in meeting deliverable deadlines, improper lifestyle of the truck drivers leading to shortage, no guarantee of the safety, etc. These have been tackled and the entire process has been automated by introducing relay travel style. The trucks travel from one point to the other in a relay system as a result of which the truck drivers have proper 9-12 hours job like regular people Nair R (2018) [19]. Their safety and lifestyle has been improved by leaps and bounds. To top this facility, the trucks have GPS tracking devices attached to the tyres which prevent them from being stolen, as they are continuously tracked as a result of which replacing them is impossible while the truck is in duty. The sensors keep the tracking real time and keep providing data every second. The products transferred are also tracked, along with the fuel consumption and their speed limit. Any irregular spike will be noticed and taken care of.

\subsubsection{Use case}

This is implemented in India by a company named Rivigo. With its headquarters in Gurugram, this company has given technology a new name and a new scope. They have redefined the way trucks are used and hired in the Indian society with pit stops every $250-300 \mathrm{kms}$ apart.

\subsubsection{Impact/benefits on IT infrastructure}

The smart algorithm used is unique and one of a kind. There are apps which save the data of the fuel used, routes, products carried, etc. thus makes tracking easier and are used by the employees and the pilots continuously. The data is stored and duly processed to predict the behaviour or predict the corrective steps to make the process smoother.

Proposition 1: IoT applications have a positive impact in the area of smoother logistics management by ensuring faster delivery and better lifestyle for the people in that profession.

\subsection{IOT application 2: Waste Management:}

\subsection{Technology adopted}

Waste containers are all connected over the network via sensors which read the humidity, the amount of the waste, the type of the waste as well as the temperatures. This data once collected is then analyzed by the sanitation department who plan the waste collection routes deftly by updating the truck routes based on the analysis. It has helped in judicial management of waste (Maurício et al 2016) [20]. Few countries are adopting solar powered compact bins. The fill information of the bin is updated in the sensors attached thus ensuring timely disposal. These are of specific standard, which helps maintain the equipment for disposal. This process reduces the number of trips the trucks make for dump collection thus keeping the streets clean and reducing pollution to a great extent (Gelsin A, 2017) [21].

\subsubsection{Use cases}

This technology has been vastly adopted in several cities like Amsterdam, Melbourne, Atlanta, Philadelphia, Seoul and Dublin.

\section{2.3 Impact/benefits on IT infrastructure}

This process will ensure that the Wi-Fi network coverage is strong over the entire city and all the bins are well connected, continuously updated the fill level. Area specific waste data is collected and processed with algorithms for studying the pattern of waste generated from a particular area. This can improve the rate of collection and selecting the kind of trucks for that area and its duration.

Proposition 2: IoT applications have a positive impact in the area of Waste management solutions as they help make the city cleaner and healthier.

\subsection{IOT application 3: Reducing Crime Rates}

\subsection{Technology adopted}

There are three kinds of sensors used to capture details and transfer it for further processing. The first kind is the static sensors which are used to measure the temperature, the humidity, the light, the pressure noises, etc. The dynamic sensors are used in cars or buses to capture their movement and to read their speed and different acceleration, etc. The third kind is the participatory sensors which are used by the citizens to send the information over to the police in case of any accidents or breaking of rules or emergency (Bouskela M, 2016) [20]. This helps the city to keep a continuous eye on the happenings in the city, on every street. There are ten panels which are located at the entrance if the city, the drivers are informed well before hand about the parking spaces in the downtown areas.

\subsubsection{Use cases}

This technology has been implemented in Santander, Spain to help the city live a comfortable live and stay safe and aware of the happenings in the city.

\subsubsection{Impact/benefits on IT infrastructure}

The sensors are all connected to the cloud which updates it database constantly and people have applications which keep them informed. They can also check the bus routes, the timings, the congestion on the street with the help of the application, thereby making it more time efficient and removing pollution. The sensors keep capturing the data and are updated with the help of the fast processing by the algorithms installed. This has brought down the crime rate in the city.

Proposition 3: IoT applications have a positive impact in the area of safety solutions which will lead to reduction of crime rate thus making the life safer for the people in that city. 


\section{V.FUTURE APPLICATIONS}

IoT has been implemented in several cities as a part of their smart city program in order to simplify the standards of living and making the environment safe, healthy and sustainable. There are however certain projects which can be implemented in the near future and has a lot of scope in making lives easier. These however come with its own set of pros and cons but once a workaround is sought out, then it will certainly make living simple.

\subsection{Making real-estate easy with Data Analytics:}

\subsubsection{Real-Estate implementation Use case}

Using the foot data traffic in a certain area or a surrounding can give a clear idea of the people visiting that area per day. In order to set up a retail store this data will provide of great advantage to create a predictive analysis (Anshuman, 2018) [22]. This can also be used by someone looking for buying a house in a certain quiet neighbourhood.

\subsubsection{Impact of this technology}

The data can be used in a predictive analysis algorithm to analyse the number of people treading the area and this will help make the decision more in sync with the cause. The data is not easy to get the hands on as the Government has not released these data yet, but in the future if there is a possibility to secure the data without risking the identity then this can be implemented.

Proposition 4: IoT applications can have a positive impact in the area of Real estate solutions as it will help make it easier for government to give better housing solutions and help residents in making better choices.

\subsection{Making Self Driven Cars a reality}

\subsubsection{Self-Driven Cars implementation}

This technology is under continuous analysis and is supposed to predict the behaviour of a vehicle based on the past behaviour of the traffic, the road, etc. There are certain external costs which need to be taken account of as well as availability of constant internet connection. These vehicles will be connected to the cloud network and will be constantly updated with the activities in the street in which they are heading (Litman, T. 2019)[23]. On top of that they need to have sensors which can predict movement around the cars and pull the breaks on time to avoid collision.

\subsubsection{Impact of this technology}

This is a very costly technology and would need the network to have extremely smooth internet connectivity that keeps the data updated every fraction of a second. The GPS must be strong enough to predict the path and the obstacles in the ways. This also needs sensors which will be able to stop the car in case there are obstacles, or predict the traffic lights. There also needs to be security cameras installed in the cars to keep a track of all the happenings in the car for security purpose.

Proposition 5: IoT applications can have a positive impact in the area of Automotive solutions as it will help making travel easier, smoother and less tiring for the drivers as well as the people travelling for work as well as leisure purpose.

\section{IMPLICATIONS OF RESEARCH AND FUTURE DIRECTIONS\& RESULTS}

The study will be useful for academicians as it adds to literature on leveraging IoT technologies for IT Infrastructure management, for practitioners to design and develop solutions for smart city infrastructure and to the society well being as it provides implications to Government official in terms of how to plan smart city infrastructure.

The above cases justify that Internet of Things has a lot of applications in IT infrastructure for making cities smarter. We have seen the applications of this technology in varied areas of logistics, waste management, crime reduction, real estate and automotive industry. This technology has a positive impact on the city as well as people residing in the city by way of smoother logistics management ensuring faster delivery and better lifestyle for the people in that profession. Waste management solutions help in making the city cleaner and healthier. Safety solutions will lead to reduction of crime rate thus making the life safer for the people in that city. Real estate solutions will make it easier for government to give better housing solutions and help residents in making better choices. Automotive solutions will help making travel easier, smoother and less tiring for the drivers as well as the people travelling for work as well as leisure purpose.

The prospect of IoT is in abundance and with the proper technological analysis there resides a great deal of scope to use for improving the lives of the people. India has already a lot of techniques with the help of which it is able to make the lives of their citizen simpler but it needs to delve deeper into it and introduce the aforementioned techniques to ensure road safety, waste management, etc. The network coverage and connectivity needs to be of top quality to ensure there are no glitches in the path. India needs to put in sync their cameras with the geographical information sensors to ensure they have a live update of the activities on the road and also to avoid any safety threat. The cloud system in India needs to connect to a stronger network and the connectivity needs to be set up at well stretched margins.

Future research can be done in this area to find out the feasibility of the above mentioned IoT technologies in the areas of real estate and self-driven cars especially in the Indian context. Secondly the impact of these technologies also need to be studied along-with the feasibility as it will then help decide if these technologies should be implemented in India. 


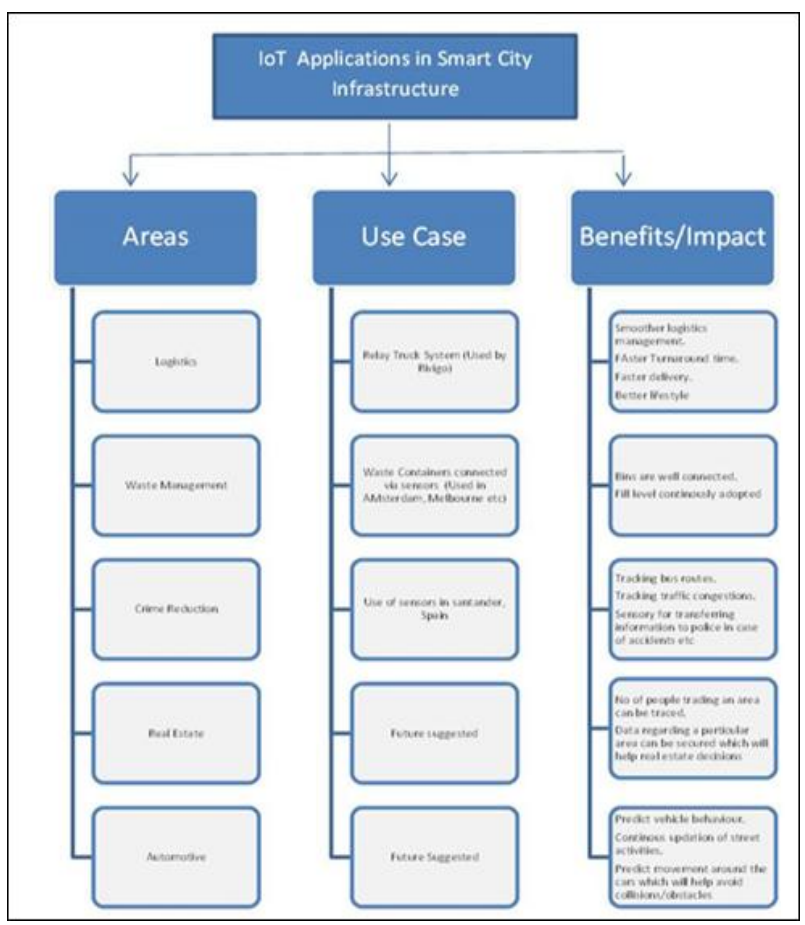

Fig 1: Areas, Use cases, Impact/benefits of IoT applications for smart cities

\section{REFERENCES}

1. Cavada, Marianna \& Hunt, D \& Rogers, Chris, "The Role of Infrastructure in Smart Cities". International Symposia for Next Generation Infrastructure, September 2017 [Online]. Available at file:///C:/Users/HP- September 2017,

PC/Downloads/Cavadaetal2017Theroleofinfrastructurein SMARTcities_ISNGI201\%20(3).pdf. Accessed on 30th May 2019

2. Chaudhary, S., "IOT and Impact on Smart Cities". Indian Web 2, April 29th, 2018. [Online] Available at: https://www.indianweb2.com/2018/04/29/iot-and-impact -on-smart-cities Accesses on: 25th May 2019

3. Xcube LABS, "How IoT Is Providing A Smart Infrastructure For Remodelling A City? Xcube Labs Blog. July 28th 2017. [Online] Available at: https://www.xcubelabs.com/our-blog/iot-for-remodelling -city/

4. Gurnaney T, "Future picture: Why India will need Internet of Things to bring in major transformation". ET Telecom, November 22, 2017). [Online] Available at https://telecom.economictimes.indiatimes.com/news/futu re-picture-why-india-will-need-internet-of-things-to-brin g-in-major-transformation/61729747 Accessed on 25th May 2019

5. Steinbach R (2018, April 30). "How India can benefit from IoT?" DigiAnalyses. April 30th 2018. [Online]. at: https://www.digianalysys.com/how-india-can-benefit-fro $\mathrm{m}$-iot

6. Lea, Rodger \&Blackstock, Michael, "City Hub: A Cloud-Based IoT Platform for Smart Cities. Proceedings of the International Conference on Cloud Computing Technology and Science", CloudCom, 799-804, 2015. 10.1109/CloudCom.2014.65

7. J. Paradells, C. Gómez, I. Demirkol, J. Oller and M. Catalan, "Infrastructureless smart cities. Use cases and performance". 2014 International Conference on Smart Communications in Network Technologies (SaCoNeT), Vilanova i la Geltru, pp. 1-6, 2014. Doi: 10.1109/SaCoNeT.2014.6867772

8. Ouerhani, Nabil \&Pazos, Nuria\&Aeberli, Marco Available

\&Muller, Michael, " IoT-based dynamic street light control for smart cities use cases". International Symposium on Networks, Computers and Communications (ISNCC), 1-5, 2016. Doi: 10.1109/ISNCC.2016.7746112

9. Perera, C., Qin, Y., Estrella, J. C., Reiff-Marganiec, S., \&Vasilakos, A. V, "Fog Computing for Sustainable Smart Cities: A Survey". ACM Computing Surveys, 50(3), 2017. https://doi.org/10.1145/

10. Ganesh, E.N, "Development of Smart City Using IOT and Big Data". International Journal of Computer Techniques., vol. 4, issue 1, pp. 36-41, February, 2017

11. Nassar, Ahmed \&Montasser, Ahmed \&Abdelbaki, Nashwa, "A Survey on Smart Cities' IoT". International Conference on Advanced Intelligent Systems and Informatics, pp 855-864, 2018. Doi: 10.1007/978-3-319-64861-3_80

12. Zhang Z, Zhang L, Yang Y, Kang Q, Sun D, "Object Tracking for a Smart City Using IoT and Edge Computing". Sensors (Basel). 19(9). pii: E1987, 2019. doi: 10.3390/s19091987

13. Parishwad, O., Singh, T., "Analysing and Rating Smart City Development in India". Journal of Civil Engineering and Environmental Technology. Volume 1, Number 6, pp. $54-59,2014$

14. Tiwary, AkhilendraNath, "Prospects and Constraints in Development of Varanasi as Smart City, India". International Journal of Advanced Scientific Research and Management, Vol. 1 Issue 3, pp. 71-80, 2016

15. Yin, R.K., "Case Study Research: Design and Methods" Beverly Hills, Calif: Sage Publications, 1984.

16. Gummesson, E., "Qualitative Methods in Management Research". Sage Publication, California, pp: 83-156, 1981

17. McDonough, J. and McDonough, S., "Research Methods for English Language Teachers". London: Arnold, 1997

18. Hou, Lu \& Zhao, Shaohang\&Xiong, Xiong\&Zheng, Kan\&Chatzimisios, Periklis\&Hossain, M. Shamim\& Xiang, Wei, "Internet of Things Cloud: Architecture and Implementation". IEEE Communications Magazine. 54(12) pp 1-19, $2016 . \quad$ DOI: 10.1109/MCOM.2016.1600398CM

19. Nair R, "Rivigo shows how a humane but tech-enabled logistics company can command a billion-dollar valuation". Your Story. March 12th 2018 [Online].Available at: https://yourstory.com/2018/03/rivigo-billion-dollar-valua tion-journey

20. MaurícioBouskela, MárciaCasseb, Silvia Bassi, Cristina De Luca y Marcelo Facchina, "The Road toward Smart Cities Migrating from Traditional City Management to the Smart City" p. cm. - (IDB Monograph; 454), 2016

21. Gelsin, A., "Smart Waste Management Solutions in Smart Cities". Bee Smart City. August 31st, 2017. [Online] Available at: https://hub.beesmart.city/solutions/en/smart-environment /smart-waste-management-solutions-in-smart-cities Accessed on 30t May 2019

22. Anshuman, M, "Smart Cities: Transforming the Future of Real Estate in India". BW Smart cities, July 16th, 2017. [Online] Available at: http://bwsmartcities.businessworld.in/article/Smart-Cities -Transforming-The-Future-Of-Real-Estate-In-India/16-0 7-2018-154904/ Accessed on 25th May 2019

23. Litman, T, "Autonomous Vehicle Implementation Predictions Implications for Transport Planning". VTPI, March 18, 2019. [Online]. Available at: https://www.vtpi.org/avip.pdf, Accessed on 30th May 2019. 